\title{
Somatostatin Analog Therapy
}

National Cancer Institute

\section{Source}

National Cancer Institute. Somatostatin Analog Therapy. NCI Thesaurus. Code C15449.

Endocrine drug therapy that uses analogs of somatostatin to treat neuroendocrine tumors. 